\title{
Characteristics of the Epididymal Luminal Environment Responsible for Sperm Maturation and Storage
}

\author{
Wei Zhou', Geoffry N. De Iuliis', Matthew D. Dun ${ }^{2,3}$ and Brett Nixon ${ }^{1 *}$ \\ ${ }^{1}$ Priority Research Centre for Reproductive Science, School of Environmental and Life Sciences, University of Newcastle, \\ Callaghan, NSW, Australia, ${ }^{2}$ Faculty of Health and Medicine, University of Newcastle, Callaghan, NSW, Australia, \\ ${ }^{3}$ Cancer Research Program, School of Biomedical Sciences and Pharmacy, Hunter Medical Research Institute, \\ University of Newcastle, New Lambton Heights, NSW, Australia
}

OPEN ACCESS

Edited by:

Marc Yeste,

University of Girona, Spain

Reviewed by:

Robert Sullivan,

Laval University, Canada

Jean-Louis Dacheux,

UMR7247 Physiologie de la reproduction et des comportements

(PRC), France

*Correspondence:

Brett Nixon

brett.nixon@newcastle.edu.au

Specialty section: This article was submitted

to Reproduction,

a section of the journal

Frontiers in Endocrinology

Received: 14 December 2017

Accepted: 09 February 2018

Published: 28 February 2018

Citation:

Zhou W, De luliis GN, Dun MD and Nixon B (2018) Characteristics

of the Epididymal Luminal

Environment Responsible for

Sperm Maturation and Storage.

Front. Endocrinol. 9:59.

doi: 10.3389/fendo.2018.00059
The testicular spermatozoa of all mammalian species are considered functionally immature owing to their inability to swim in a progressive manner and engage in productive interactions with the cumulus-oocyte complex. The ability to express these key functional attributes develops progressively during the cells' descent through the epididymis, a highly specialized ductal system that forms an integral part of the male reproductive tract. The functional maturation of the spermatozoon is achieved via continuous interactions with the epididymal luminal microenvironment and remarkably, occurs in the complete absence of de novo gene transcription or protein translation. Compositional analysis of the luminal fluids collected from the epididymis of a variety of species has revealed the complexity of this milieu, with a diversity of inorganic ions, proteins, and small non-coding RNA transcripts having been identified to date. Notably, both the quantitative and qualitative profile of each of these different luminal elements display substantial segment-to-segment variation, which in turn contribute to the regionalized functionality of this long tubule. Thus, spermatozoa acquire functional maturity in the proximal segments before being stored in a quiescent state in the distal segment in preparation for ejaculation. Such marked division of labor is achieved via the combined secretory and absorptive activity of the epithelial cells lining each segment. Here, we review our current understanding of the molecular mechanisms that exert influence over the unique intraluminal environment of the epididymis, with a particular focus on vesicle-dependent mechanisms that facilitate intercellular communication between the epididymal soma and maturing sperm cell population.

Keywords: epididymis, sperm maturation, intracellular communication, protein trafficking, apocrine secretion, merocrine secretion, epididymosome, dynamin

\section{INTRODUCTION}

The mammalian epididymis is an exceptionally long, convoluted ductal system that serves to connect the ductuli efferentes, which drain the testes, to the ductus deferens. Anatomically, this highly specialized organ is generally divided into four broad segments: the initial segment, caput, corpus, and cauda epididymides (Figures 1A,B) (1); although this demarcation is not strictly adhered to in all mammalian species (2). Irrespective, the epididymis is responsible for the 


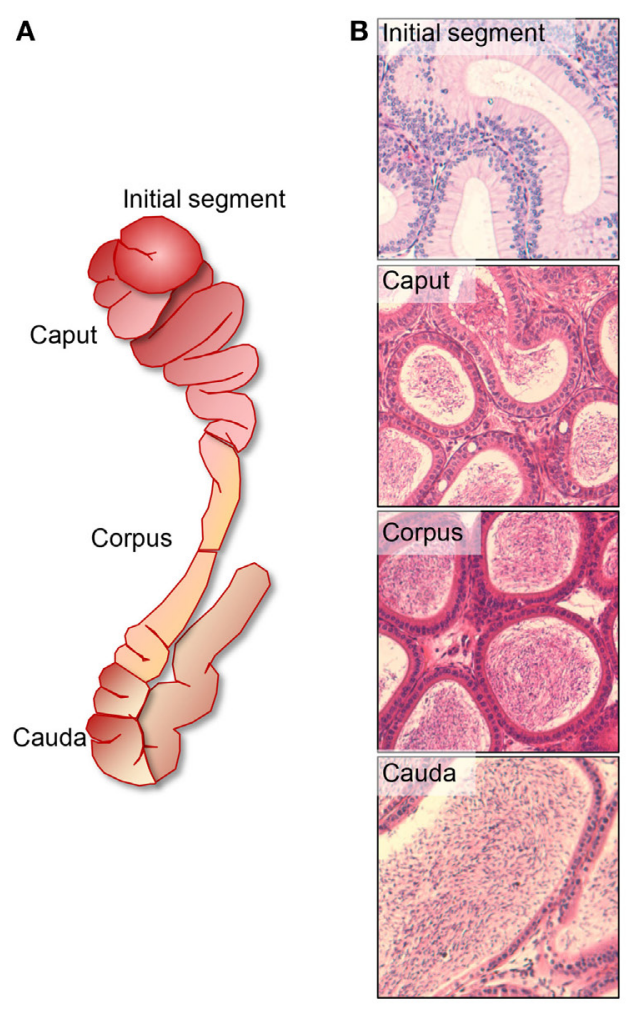

C

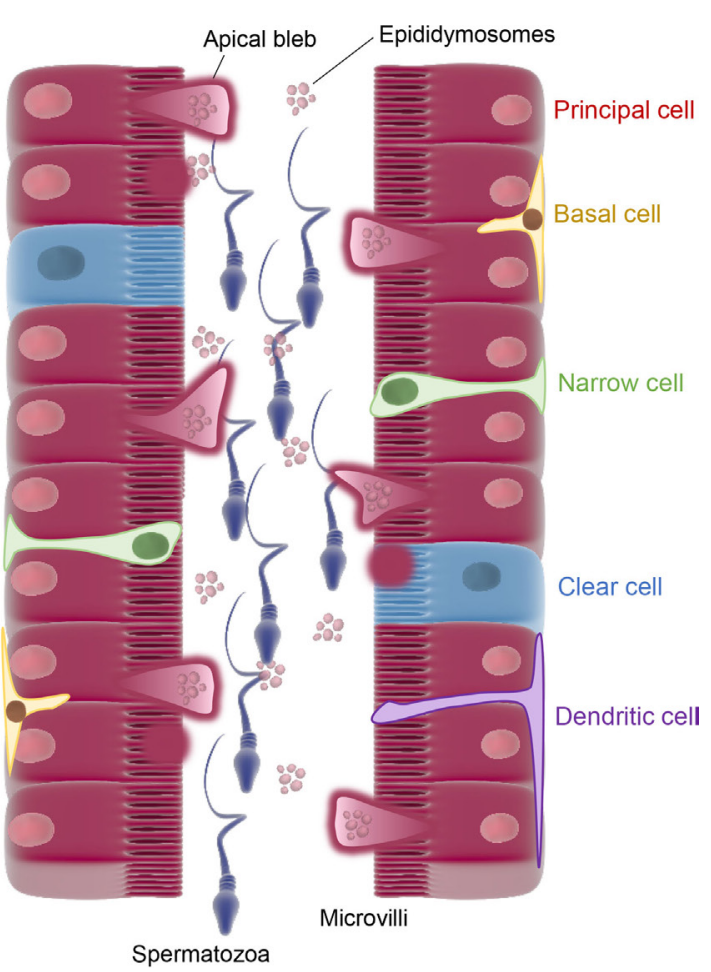

FIGURE 1 | Regionalized structure and schematic distribution of the major cell types in the mouse epididymis. (A,B) The mouse epididymis is generally broadly divided into four unique anatomical segments: the initial segment, the caput, corpus, and cauda epididymis. The initial segment is a loosely coiled tubule with a wide diameter and a low concentration of spermatozoa. Epithelial cells in this segment are elongated and possess high stereocilia. The caput segment is characterized by a narrow luminal diameter, while both the luminal diameter and the sperm concentration increase distally within the corpus and cauda epididymis. Differing cell types within these segments are responsible for the creation of a specialized luminal microenvironment that promotes the sequential maturation of spermatozoa (caput and corpus epididymis) and their subsequent storage (cauda epididymis). (C) Principal cells dominate the soma along the entire length of epididymis and are particularly active in terms of protein biosynthesis and secretion in the proximal epididymal segments. In this context, an apocrine pathway of secretion, featuring the formation and eventual shedding of large bleb-like structures from the apical margin (i.e., apical blebs) of principal cells, appears to be a dominant secretory mechanism operating in all epididymal segments. Upon degradation within the epididymal lumen, apical blebs release a heterogeneous population of membranous extracellular vesicles, termed epididymosomes, which have been implicated in intracellular communication with spermatozoa and downstream epithelial cells. Aside from principal cells, clear cells are distributed sporadically throughout the epithelium of the caput, corpus, and cauda segments in most studied species and are primarily responsible for selective absorption of luminal components and conversely, the regulation the luminal pH. A suite of additional cell types have been described in the epididymis, including basal cells, apical cells, halo cells, narrow cells (only found in initial segment and intermediate zone), and immunological cells.

provision of an optimal environment to promote the functional transformation of spermatozoa and their subsequent storage in viable state in readiness for ejaculation. Functional profiling studies indicate that the epididymis displays highly regionalized characteristics. Thus, the initial segment and upstream ductuli efferentes are responsible for the absorption of the majority of testicular fluid entering the duct leading to a pronounced concentration of the luminal spermatozoa (3). Thereafter, the caput epididymis is most active in terms of protein synthesis and secretion, and a small portion of the sperm passing through this region begin to exhibit the ability to swim in a progressive manner and to recognize an oocyte (4-6). These functional characteristics continue to develop in the corpus epididymis before reaching an optimal level in the distal caudal segment. This latter region is characterized by a relatively large lumen and its surrounding epithelial cells exhibit strong absorptive activity $(7,8)$. Such attributes align with the dominant function of the cauda epididymis in terms of the formation of a sperm storage reservoir.

It is well established that the combined secretory and absorptive activities of the epididymal epithelial cells are responsible for the creation of the highly specialized luminal microenvironment that promotes the gradient of increasing fertility in the sperm population held therein (9). Systematic analysis of the composition of these luminal fluids has revealed a complex macromolecular landscape encompassing a myriad of soluble factors in addition to non-pathological amyloid matrices and exosome-like vesicles termed epididymosomes. The latter of these have come under increasing scrutiny owing to their potential to facilitate the efficient transfer of a variety of protein and small non-coding RNA cargo to the maturing sperm cells. Furthermore, there is emerging evidence that the epididymosome payload may be dynamically altered in response to paternal exposure to environment stressors. The implications of such changes in terms of 
establishing the sperm epigenetic and proteomic signatures, and their potential to influence the downstream health and developmental trajectory of offspring, are only just beginning to be realized. It is therefore timely to review the changes associated with sperm maturation in the epididymal tract and the molecular mechanisms by which such changes are brought about. Here, we focus on the regulation of the epididymal luminal microenvironment and place particular emphasis on vesicle-dependent mechanisms that facilitate intercellular communication between the lining epididymal soma and the maturing sperm cell population.

\section{THE LUMINAL MICROENVIRONMENT OF THE EPIDIDYMIS}

The process of post-testicular sperm maturation is reliant on the highly specialized intraluminal microenvironment of the epididymis, arguable one of the most complex milieus produced by any endocrine gland. Accordingly, the selective ablation of genes that lead to dysregulation of the epididymal microenvironment commonly results in male infertility/subfertility phenotypes (Table 1). The origin of these fluids rests with the pseudostratified epithelium lining the duct. This epithelium comprises a number of different cell types (Figure 1C) including, populations of principal, clear, narrow, apical, basal, halo, and immunological (macrophage and dendritic) cells; the abundance of which varies considerably between different epididymal segments (10). Detailed functional studies have confirmed spatial differences in the profile of each cell type and revealed that, under the precise control afforded by androgens and various other factors of testicular origin, they each make unique contributions to sperm maturation, protection, and storage (10).

\section{Epididymal Epithelium}

Principal cells represent the major cell type throughout the entire epididymis, constituting as much as $80 \%$ of the peritubular interstitium (11). These cells are characterized by abundant secretory apparatus [endoplasmic reticulum (ER), Golgi and secretory granules] reflecting their high exocytotic activity, especially in the proximal portions of the epididymis (caput and corpus) $(8,12,13)$. In more distal segments (cauda), the principal cells take on a predominantly endocytotic role in which they are actively responsible for the reabsorption of various components from the epididymal fluid, a function that is also shared with that of the clear cell population (12). Clear cells are the second most abundant cell type, being widely distributed in the caput and corpus segments but displaying most enrichment in the cauda. The apical domain of clear cells is replete with endocytotic apparatus and accordingly, these cells have a tremendous capacity for endocytosis $(7,12)$. This is particularly true of the clear cells that populate the distal epididymal segments, which have been implicated in the uptake and disposal of the cytoplasmic droplets that are shed from the maturing sperm cell population (7), as well as the recycling of various other luminal components. Also within their apical domain, clear cells possess key elements of the machinery [vacuolated (V)-ATPase, carbonic anhydrase II, and soluble adenylate cyclase] necessary for acidification of the luminal environment, thus highlighting their role in regulation of the $\mathrm{pH}$ of the epididymal environment $(8,14)$. Narrow and apical cells are mainly found within the initial segment $(15,16)$. However, their function is yet to be fully resolved (8). Basal cells display a hemispherical morphology and form intimate contact with the basement membrane and principal cells on both sides (8).

TABLE 1 | Gene knockout or deletion strategies that impact the intraluminal environment of the mouse epididymis.

\begin{tabular}{|c|c|c|c|}
\hline Gene knockout & Fertility phenotype & Changes to epididymal environment & References (PMID) \\
\hline Sed1 & Infertile & $\begin{array}{l}\text { Hypo-osmotic and alkaline epididymal fluid, disrupted fluid } \\
\text { reabsorption, increased intracellular vesicles }\end{array}$ & 20122713 \\
\hline Esr1 & Infertile & Hypo-osmotic fluid & 20130266 \\
\hline C-ros & Infertile & Defective initial segment development, increased luminal pH & 10645273,15095336 \\
\hline Dicer1 & Subfertile & $\begin{array}{l}\text { Imbalanced lipid homeostasis in proximal segments. Dedifferentiation } \\
\text { of the epithelium and imbalance in sex steroid signaling }\end{array}$ & 25366345,22701646 \\
\hline$R / x$ & Subfertile & Delayed maturation and growth associated with increased collagen deposition & 15956703 \\
\hline He6 & Infertile & Reduced in size and dysregulation of fluid reabsorption & 15367682 \\
\hline $\begin{array}{l}\text { Lur (testosterone } \\
\text { treatment) }\end{array}$ & Subfertile & Inflammation in epididymis & 15514086 \\
\hline Er $\alpha$ & Infertile & $\begin{array}{l}\text { Disruption in } \mathrm{Na}^{+} \text {reabsorption and passive water transport, } \\
\text { abnormal epithelial ultrastructure }\end{array}$ & 11698654 \\
\hline Nhe3 & Infertile & Disruption in $\mathrm{Na}^{+}$reabsorption and passive water transport & 11698654 \\
\hline$L x r$ & Infertile & Abnormal accumulation neutral lipids & 15525595 \\
\hline Apoer2 & Infertile & Dysfunction of clusterin and PHGPx protein impacting sperm maturation & 12695510 \\
\hline Fsh-r & Subfertile & Smaller epithelial surface area in caput and corpus segments & 15973687 \\
\hline Gpx5 & $\begin{array}{l}\text { Higher incidence of } \\
\text { miscarriages and } \\
\text { developmental defects }\end{array}$ & $\begin{array}{l}\text { Excess of reactive oxygen species in the cauda segment leading } \\
\text { to oxidative damage of spermatozoa }\end{array}$ & 19546506 \\
\hline Hoxa10 & Subfertile & Epididymis characterized by homeotic transformation & 8787743 \\
\hline Hoxa11 & Infertile & Epididymis characterized by homeotic transformation & 7789268 \\
\hline Hexa & Infertile (age dependent) & Inability to degrade endocytosed substrates & 12617783 \\
\hline $\operatorname{Tmf}$ & Infertile & Epithelial apoptosis and sperm stasis in the cauda segment & 23000399 \\
\hline Trpv6 & Subfertile & Defects in epididymal $\mathrm{Ca}^{2+}$ absorption & 22427671 \\
\hline Slc9a3 & Infertile & Abnormally abundant secretions and calcification in the lumen & 28384194 \\
\hline
\end{tabular}


Ligation experiments in the rat have shown that basal cells possess the ability to change shape in order to adjust the luminal volume and pressure; features that are suggestive of a protective role in preserving the structural integrity of the lumen (17).

The remaining cell types comprising the epididymal epithelium are predominantly related to immune functions (8), an important consideration given the highly antigenic nature of the male germ cell. Indeed, the epididymal luminal environment and thus maturing spermatozoa are shielded from immune surveillance behind a blood-epididymal barrier. This barrier consists of a network of tight junctions that form between adjacent epithelial cells. The ductal system so created is further characterized by connective septa to form a number of distinct segments and thus facilitate the formation of successive, regionally distinct luminal microenvironments (18-20). Since a majority of testicular fluid is reabsorbed before reaching the proximal segments of the epididymis, most of the luminal components, other than the sperm cells themselves, originate from the secretory activity of the pseudostratified epithelial cells comprising the duct. Detailed compositional analysis of the epididymal fluid has revealed it contains a complex array of proteins, ions, and small non-coding RNA species $(21,22)$. While these molecules are present in all the epididymal segments, they nonetheless display an extraordinary level of regionalization, which reflect differential secretory and absorptive activity of the epithelial cells.

\section{Luminal Components}

As previously mentioned, the proteome of maturing spermatozoa is substantially modified via the uptake, repositioning, and posttranslational modification of a significant portion of proteins. Such changes are mediated by direct exposure to the proteins secreted into the epididymal luminal environment, with a majority of these originating in the proximal segments of the caput and corpus epididymis (23). By contrast, proteins involved in the preservation of sperm viability, such as antioxidant enzyme defenses, and those responsible for suppression of humoral immune responses, tend to be enriched in the cauda epididymal secretome (23). Furthermore, detailed transcriptomic analysis in the mouse epididymis has identified a prominent theme of segment-dependent regulation, with the expression of $12.8 \%$ of the total 17,000 epididymal genes being characterized by changes of at least fourfold between any two segments (21). This ratio increases to $35.8 \%$ if the criterion is relaxed to include transcripts that vary by at least twofold. Consistent with these data, it has also been shown that protein and gene expression patterns display very discrete profiles that closely align with the borders of septa demarcating anatomically different segments of the epididymis (24-26). How this precise regulation is imposed is still unclear, but it is perhaps notable that grossly similar profiles of epididymal protein expression have been documented along the epididymal tract of many mammalian species, including large domestic species (27) and humans (28). One possible explanation rests with evidence for the expression of a myriad of small non-protein coding RNA transcripts in the epithelial cells (22, 29-33).

In this context, the focus for most investigations has been the microRNA (miRNA) class of RNA molecules ( 21-25 nucleotides) that hold a key regulatory role in the repression of mRNA translation. Indeed, the use of microarray and next generation sequencing methodologies has led to the identification of a total of 545 and 370 miRNAs in the human and mouse epididymis, respectively $(22,29)$. A large portion of these miRNAs are conserved among different epididymal segments (75\% in the mouse epididymis) and even between different species ( $31 \%$ between mouse and human), suggesting housekeeping roles in the regulation of epididymal homeostasis (22). In contrast, other miRNAs are characterized by pronounced segmental patterns of expression (15\% in mouse epididymis). For example, $m i R-204-5 p$ and $m i R-196 b-5 p$ are down and upregulated significantly, with approximately 39- and 45-fold differences in expression having been recorded between caput and caudal segments of the mouse epididymis (22). The biological implications of such differences are highlighted by the potential for each miRNA species to exert regulatory control over multiple targets. By way of illustration, target prediction algorithms indicate that an estimated 530 and 160 genes are putatively able to be targeted by $m i R-204-5 p$ and $m i R-196 b-5 p$, respectively (34). Thus, the differing miRNA expression profiles documented in each epididymal segment impose a daunting level of complexity to the regulation of unique segmental environments in the epididymis. The precise mechanisms responsible for differential miRNA expression profiles remains poorly understood but are undoubtedly influenced by androgens and other lumicrine factors of testicular origin (35). Alternatively, it has been proposed that epididymosomes may serve as vectors to selectively traffic miRNA cargo between their sites of production in the proximal epididymal segments to recipient epithelial cells lining downstream segments (36).

In any case, it is therefore perhaps not surprising that intraluminal proteome of the epididymis ranks among the most complex produced by any endocrine gland. In addition to a diversity of soluble proteins, electron-dense proteinaceous complexes have also been described in the epididymal lumen of rodents, rams and, recently humans (37-40). These are apparently nonpathological structures, with a diameter ranging from $500 \mathrm{~nm}$ to $1.2 \mu \mathrm{m}$, which lack any obvious organelles, and similarly, are not delineated by a lipid bilayer (39). Despite these features, the formation/maintenance of these extracellular matrices appears to be a selective rather than stochastic process as evidenced by the conservation of their protein profile across several taxa. In this regard, the highly amyloidogenic cystatin-related epididymal spermatogenic (CRES) family appear to be critical constituents of these entities (41). Thus, a potential mechanism for formation is through self-assembly brought about by interaction of CRES subgroup members, small hydrophobic proteins and/or prion proteins $(37,41)$. Accordingly, pioneering work by the Cornwall laboratory has established that these extracellular matrices do possess amyloid structural properties, which change along the length of the epididymal tubule. Indeed, immature amyloid forms prevail in the proximal epididymis before taking on thinner "film-like" characteristics in the distal epididymis $(41,42)$. Notably, these changes in amyloid matrix structure parallel changes in epididymal function with proximal segments responsible for promoting sperm maturation and distal segments serving 
primarily as a storage site for mature spermatozoa (please see Introduction). On the basis of these data, it has been suggested that epididymal amyloids are formed for functional purposes in sperm maturation and/or protection by coordinating interactions between the luminal fluid and spermatozoa. Interestingly, a similar role has also been proposed for "dense bodies" that have been documented in the lumen of the rodent epididymis $(39,43,44)$, although at present it remains to be established whether these amorphous entities do equate to amyloid matrices. Irrespective, dense bodies are replete with proteins such as those of the molecular chaperone family (HSPD1 and HSP90B1) (39), bactericidal/permeability-increasing protein (43), and glycogen synthase kinase 3 . While the precise function of the chaperone cargo remains obscure, it has been suggested that, similar to CRES, these proteins may assist in the aggregation of luminal proteins into large discrete entities, and thus increase the efficiency with which they are able to be delivered to the spermatozoa. In keeping with this notion, ultrastructural analyses have provided evidence that dense bodies form intimate contact with epididymal spermatozoa, and thereafter mediate the transfer of associated cargo (44). Further dissection of the structural and functional properties of these extracellular matrices promises to shed new light on the mechanisms by which the epididymal soma communicates with sperm to coordinate their maturation and storage.

In addition to amyloids/dense bodies, the epididymal lumen also features an impressive population of extracellular vesicles. Indeed, as early as 1985, Yanagimachi identified a population of small membranous vesicles residing near the surface of epididymal spermatozoa in the Chinese hamster, and subsequently predicted their potential role in cholesterol transfer to the maturing spermatozoa (45). The existence of these vesicles, now commonly referred to as "epididymosomes," has subsequently been confirmed in the epididymal fluid of a variety of other mammalian species such as mice $(46)$, rats $(47)$, bull $(48,49)$, and human (50). With defining characteristics of a relatively small size (varying from 50-500 nm), a heterogeneous cargo of macromolecules, and a membrane that is highly enriched in cholesterol (51), epididymosomes have since been implicated in promoting various aspects of sperm maturation. Such influence is mediated through either direct interaction with the sperm themselves or via indirect mechanisms involving delivery of regulatory cargo (e.g., miRNAs; see below) to epithelial cells downstream of their site of genesis.

Proteomic analysis of bull and human epididymosomes has revealed they contain a complex cargo of several hundred proteins encompassing key classes of enzymes, chaperones, structural proteins, and many more with hitherto unknown function $(52,53)$. Some of these proteins have been shown to be directly transferred to specific sperm domains during their transit through the epididymis and are, in turn, essential for promoting the functional maturity of these cells. Notable examples include macrophage migration inhibitory factor (MIF), a cytokine with a broad distribution and diverse functions in multiple tissues. During epididymal transit in the rat and bovine, MIF is transferred from epididymosomes to the fibrous sheath of the sperm flagellum and subsequently influences the motility characteristics of these cells $(54,55)$. Alternatively, $\mathrm{P} 26 \mathrm{~h} / \mathrm{P} 34 \mathrm{H}$ family members (P26h in hamster, P25b in bovine, and $\mathrm{P} 34 \mathrm{H}$ in humans) are a group of glycosyl-phosphatidylinositol (GPI)-linked proteins that are initially found within epididymosomes before becoming firmly anchored to the surface of the sperm acrosomal domain. Functional studies have revealed that these proteins are indispensable for zona pellucida binding, which is a prerequisite for successful fertilization (56-58). Other transferred proteins include membrane-associated, transmembrane, and GPI-linked candidates, and it is likely that the epididymosomes afford an important mechanism for the bulk delivery of this cargo, possibly in the form of already assembled protein complexes to the sperm cell. Direct evidence for this form of transport has been provided through in vitro co-incubation studies between spermatozoa and epididymosomes focusing on protein complexes such as the MCA4a-PMCA4b-CASK complex, which has been directly co-immunoprecipitated from epididymosomes (59). This protein complex has been shown to be transferred to the acrosomal region and mid-piece of the flagellum (which are two key functional domains in the male gamete) under optimized in vitro incubation conditions featuring the physiologically relevant $\mathrm{pH}$ of 6.5 and a high concentration of zinc $(60,61)$.

In this sense, the ionic composition of epididymal fluids is markedly different from that documented in other bodily fluids (62). Thus, the epididymal fluid contains a lower overall concentration of $\mathrm{Na}^{+}, \mathrm{Cl}^{-}, \mathrm{Ca}^{2+}$ (except for human), and $\mathrm{HCO}_{3}{ }^{-}$ ions than those that have been reported in blood plasma (62-65). These particular ionic concentrations are, in turn, tightly associated with the regulation of luminal acidification that helps keep spermatozoa in a dormant state $(66,67)$. Within the epididymal lumen, events such as sexual arousal stimulate principal cells to secrete $\mathrm{HCO}_{3}{ }^{-}$and $\mathrm{Cl}^{-}$. This change is sensed by purinergic receptors in adjacent clear cells where it leads to activation of bicarbonate-sensitive adenylyl cyclase and the downstream relocalization of proton pumping ATPases to the apical region of these cells. These pumps subsequently secrete $\mathrm{H}^{+}(66)$ leading to further acidification of the epididymal luminal environment. This cell-cell cross talk is mediated by several membrane receptors including cystic fibrosis conductance transmembrane regulator positioned in the principal cells and cognate sodium bicarbonate cotransporters (NBC) in the clear cells. Intracellular $\mathrm{Ca}^{2+}$ is also required for ATPase sequestration within the apical domain of clear cells owing to its ability to dynamically modulate the actin cytoskeleton (68). $\mathrm{Ca}^{2+}$ also plays a more direct role in the regulation of sperm functionality by virtue of its ability to enter the cell through cation channels (CATSPER) that are located in the principal piece of the sperm flagellum. Accordingly, blocking $\mathrm{Ca}^{2+}$ influx via CatSper knockout strategies leads to impaired sperm motility (69).

Finally, in addition to the more well-studied proteomic and ionic components of the epididymal luminal fluids, a number of recent studies have provided compelling evidence for the existence of myriad of small non-protein coding RNA transcripts in epididymal fluid (29-33). Such entities appear predominantly, but perhaps not exclusively, to be associated with epididymosomes $(33,70-72)$. In the mouse model, we have confirmed that epididymosomes encapsulate $>350$ different 
miRNAs. This inventory includes many miRNAs that are found in epididymosomes and epididymal spermatozoa but are apparently absent, or detected at significantly reduced levels, in the surrounding soma. Such findings are suggestive of selective packaging of the epididymosomes cargo (52). In keeping with this notion, substantial qualitative and quantitative changes have been documented in the epididymosome cargo along the length of the epididymis; including significant fold changes in the accumulation of almost half of their encapsulated miRNAs (70). These data accord with similar findings in the bull (33), and take on added significance in view of evidence that epididymosomes can convey their macromolecular payload to spermatozoa and downstream epididymal epithelial cells (33). Epididymosomes thus represent key conduits for the selective modification of the sperm proteome and epigenome during their post-testicular maturation $(71,73)$. A challenge for future studies will be to determine the extent to which this novel form of intercellular communication underpins the perturbation of the sperm epigenome arising in response to paternal environmental exposures (74).

\section{REGULATION OF THE EPIDIDYMAL LUMINAL ENVIRONMENT}

Sequential modification of the epididymal luminal milieu demands the interchange of components between the lining epithelium and the lumen. As described previously, this form of intercellular communication is carefully orchestrated by the secretory and absorptive activity of the differing populations of epithelial cells (8). Logically, the interface for a majority of these interactions is the sperm plasma membrane, a structure that is known to undergo dramatic maturational changes mediated by either direct contact with the epithelial margin or by physical exchange of luminal components. Although such exchanges undoubtedly rely on membrane trafficking activity, the precise mechanisms and the machinery involved in these events remains to be fully elucidated.

\section{Epithelial Secretion: Merocrine versus Apocrine Secretory Pathways}

Merocrine secretion is a classical pathway operative in glandular tissue whereby the endosomal network generates, packages, and finally exports cargo via exocytosis (Figure 2). The diverse proteins secreted in this fashion share the general properties of being soluble and containing a signal peptide sequence that directs them toward the ER in preparation for trafficking to the membrane (75). In the mammalian epididymis, merocrine secretion is believed to be one of the major pathways through which principal cells are able to regulate the composition of the intraluminal milieu. Accordingly, morphological characterization of this cell population has revealed they possess extremely long microvilli accompanied by numerous vesicles extending from the Golgi apparatus to the adluminal cell border; this is particularly true of the proximal caput segment, which is most active in terms of protein secretion into the lumen (76). Among the epididymal proteins secreted via the merocrine pathway, many have been implicated in forming loose electrostatic associations with the periphery of the sperm surface (77). This appears to be true of proteins such as those implicated in holding sperm in a decapacitated state, i.e., the so-called decapacitation factors (77).

The precise mechanisms controlling merocrine secretion are still relatively poorly understood. Some studies have implicated regulatory elements of classical membrane trafficking machinery, such as the Rab superfamily of monomeric GTPases (78). Although various Rab proteins are highly, and differentially, expressed in the epididymal epithelium, their ability to exert similar regulation to that described in other somatic systems remains to be verified. Alternatively, recent work in our own laboratory has focused on the characterization of the temporal and spatial expression of the dynamin family of mechanoenzymes in the mouse epididymis (79). This family of proteins is of potential interest owing to their ability to couple both exo- and endocytotic processes. Indeed, while dynamin has been best studied in the context of clathrin-coated endocytosis from the plasma membrane, it is also implicated in formation and budding of transport vesicles from the Golgi network $(80,81)$, vesicle trafficking (82), orchestrating exocytotic events $(83,84)$, and in the regulation of microtubular and actin cytoskeletal dynamics $(84,85)$. Moreover, dynamin also has the potential to fine-tune exocytotic events by virtue of its ability to control the rate of fusion pore expansion, and thus the amount of cargo released from an exocytotic vesicle. In our analysis we found that, the dynamin 2 isoform is positioned within the vicinity of the Golgi apparatus of principal cells of the caput epididymis. Further, pharmacological inhibition of dynamin 2 selectively compromised the profile of proteins secreted from an immortalized caput epididymal cell line (79). On the basis of these data, we infer that dynamin 2 may contribute to the regulation of merocrine secretion by the mouse caput epithelium.

In addition to participating in merocrine secretion, there is also compelling evidence that the epididymal epithelium is heavily reliant on apocrine secretory pathways. Notably, apocrine secretion appears to underpin the transportation and release of epididymosomes into the epididymal lumen (Figure 2). This pathway, in turn, provides a mechanism for the release of proteins lacking an ER signal peptide and/or containing a glycosyl-phosphatidylinositol (GPI) anchor $(86,87)$; neither of which could be delivered to the epididymal luminal environment via the merocrine secretory pathway. As documented above, the epididymosomes released via apocrine secretion also contain a comprehensive profile of miRNAs and other sncRNAs, that themselves display marked segment specific differences (70). During intracellular transfer, the small epididymosome vesicles are first sequestered into large bleb-like structures that protrude from the apical margin of principal cells. The apical blebs eventually detach and disintegrate to release their encapsulated cargo within the lumen $(11,88)$. At present, the precise mechanisms by which the blebs are formed and detached remain to be determined. However, performed under conditions of stringent fixation, ultrastructural electron microscopy has revealed that the attachment of the apical blebs progressively narrows to form a stalk-like process that eventually undergoes scission to release the bleb into the lumen (88). This process 


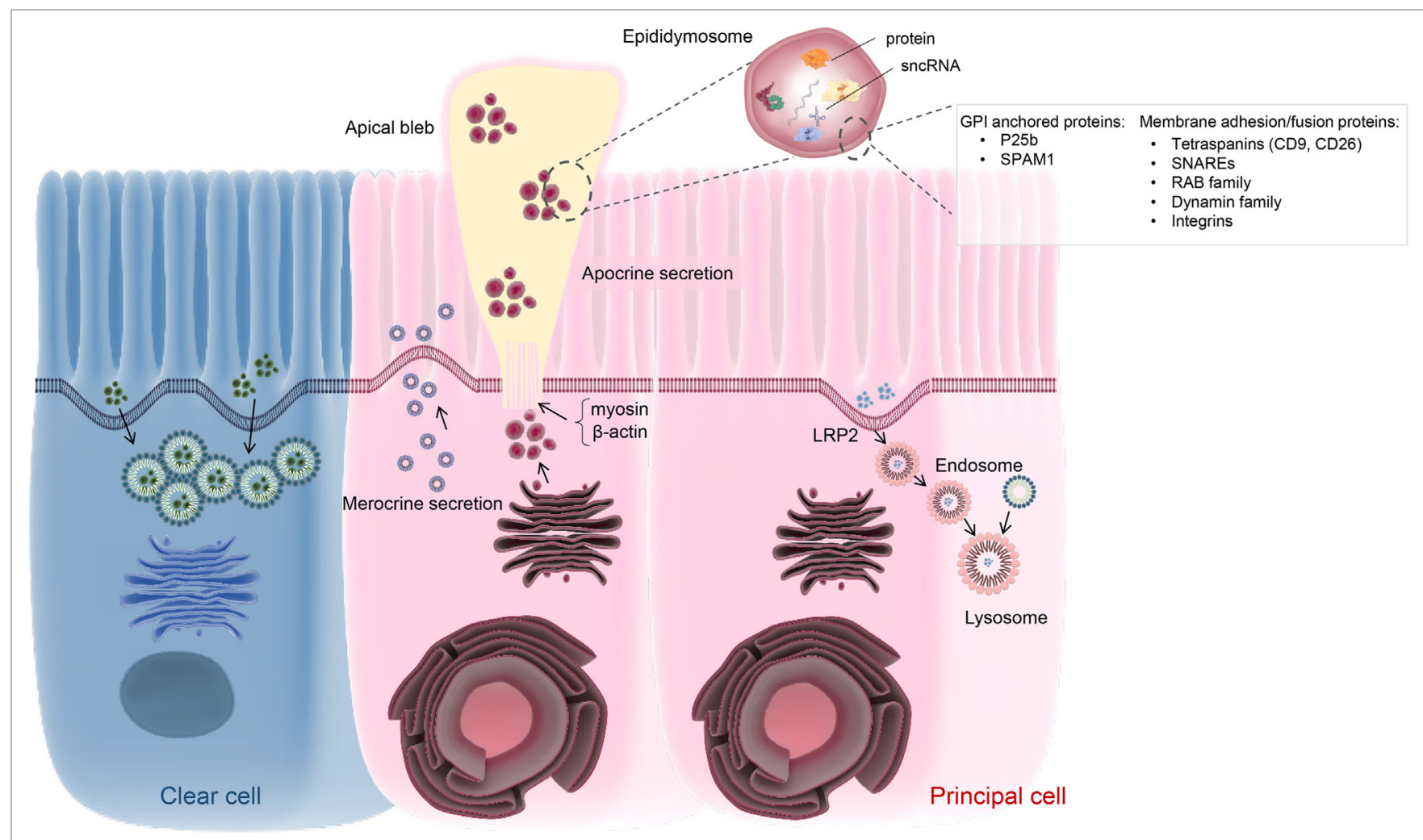

FIGURE 2 | Schematic of vesicle-dependent mechanisms that contribute to the creation of the highly specialized epididymal intraluminal milieu. Principal cells represents the dominant cell type throughout the length of the epididymis and are particularly active in terms of protein biosynthesis and secretion. At least two active secretory pathways have been documented in these cells, namely classical merocrine secretion and an alternative apocrine secretory pathway. The former is characterized by secretory vesicles formed by the Golgi apparatus and leads to the release of a myriad of soluble proteins. In contrast, apocrine secretion provides a pathway for the secretion of glycosyl-phosphatidylinositol-linked proteins and other hydrophobic proteins. These proteins generally require posttranslational modification in the Golgi apparatus, prior to being selectively packaged into exosome-like vesicles referred to as epididymosomes. These small vesicles are sequestered into large bleb-like structures protruding from the apical margin of the epithelial cells. The attachment anchoring the blebs to their parent cell progressively narrows to form a stalk-like process (potentially through reorganization of cytoskeletal proteins such as myosin and $\beta$-actin) and eventually undergoes scission leading to their shedding into the lumen and eventual degradation. The epididymosomes so released provide a mechanism for intercellular communication, thereby enabling the delivery of a complex macromolecular payload to recipient cells in the form of luminal spermatozoa and/or downstream epithelial cells. Such cargo are known to include several hundred proteins as well as various species of small non-protein coding RNA (sncRNA). At present, the mechanisms by which epididymosomes are tethered, and deliver their cargo, to recipient cells remains to be equivocally determined although various proteins have been implicated in this process. Principal cells may also participate in endocytosis, involving the uptake of epididymal luminal contents via receptor (e.g., LRP2) mediated mechanism(s). A similar function has also been assigned to the clear cell population, which is mainly responsible for the recycling of luminal components.

appears to involve reorganization of cytoskeletal proteins such as myosin and $\beta$-actin $(46,89)$. In any case, the release of the epididymosomes into the luminal environment ideally positions this heterogeneous vesicle population to interact with the maturing spermatozoa.

\section{Epithelial Absorptive Pathways}

The epithelial cells lining the initial segment of the mature mammalian epididymis have been shown to be very active in the uptake and recycling of the testicular contributions that enter the tract (3). One putative pathway for this absorption has been alluded to on the basis of apolipoprotein (apo) E receptor-2 (APOER2) expression in the principal cells of the initial segment. In this position, the APOER2 receptor is responsible for the clearance of clusterin, a glycoprotein implicated in lipid transport from spermatozoa to the principal cells. Accordingly, the inhibition of
APOER2 leads to the accumulation of clusterin in the epididymal fluid (90). Additional luminal components such as androgen binding protein, transferrin, and alpha2-macroglobulin also appear to be recycled following selective adhesion to receptors located in the adluminal domain of principal cells; a portion of which are located in the initial segment, while others present with more diffuse localization throughout the downstream segments of the epididymis. While a portion of these proteins appear destined for disposal (91-93), others such as androgen binding protein have proven to be indispensable for the normal functioning of the epididymal principal cells (91). The balance of evidence indicates that, in contrast to the initial segment, the bulk of the absorptive and recycling activity of the distal epididymal regions (and in particular the cauda epididymis) resides in clear cells. This is certainly the case for immobilin, a large glycoprotein that is responsible for the creating of the 
viscoelastic luminal environment that serves to mechanically immobilize spermatozoa $(94,95)$. Immobilin is predominantly secreted into the proximal caput epididymis prior to the acquisition of the potential for sperm motility. Thereafter, immobilin forms an intimate association with the maturing sperm cells and physically restricts the propagation of a flagellar beat. In contrast, the principal cells of more distal segments secrete minimal immobilin, while the corresponding population of clear cells begins the task of absorbing excess immobilin (95). Differing patterns of absorption have been documented for alternative proteins such as that designated as epididymis-specific Inactive ribonuclease-like protein 10 (Protein Train A) (96); a protein that is secreted into the anterior segment of the bull epididymis via a classical merocrine pathway. Thereafter, Train A experiences a rapid reabsorption, such that this protein is unable to be detected in the epididymal lumen immediately adjacent to its site of secretion (96).

Receptor-mediated absorption is also involved in the recycling of the epididymal luminal contents (Figure 2). In this context, clusterin again serves as an interesting example. Indeed, in addition to the clusterin isoform that originates in the testes (and is subsequently absorbed by principal cells of the initial segment), an alternative isoform is abundantly secreted into the lumen of the proximal epididymis, whereupon it has been implicated in sperm maturation. Both in vivo and in vitro studies have revealed that epididymal sourced clusterin is recycled by downstream principal cells via interaction with low density lipoprotein receptor (LRP-2) (97). Accordingly, clusterin and LRP-2 are both found in association with the apical surface, coated pits, endocytic vesicles, and early endosomes of principal cells. Subsequently, only clusterin is detected in late endosomes and lysosomes, suggesting that LRP-2 is recycled back to the apical surface while clusterin is delivered to the lysosomes for degradation (97). This process can be prevented by presenting the cells with an excess of protein substrates that competitively bind to LRP-2. Such receptor-dependent recycling of luminal components is a commonly encountered phenomenon within the epididymis, with additional examples including transferrin and $\alpha 2$-macroglobulin (93). Epididymal epithelial cells also possess the ability to monitor the luminal environment and adjust their absorptive ability accordingly. In this context, the estrogen receptor $\alpha(\mathrm{ER} \alpha)$ has been identified as key sensor involved in the regulation of fluid reabsorption in the efferent ducts and initial segment of the epididymis. This system is apparently fine-tuned by a ubiquitin-dependent proteasome pathway that affords precise control over ER $\alpha$ turnover and degradation (98). Another interesting example of this phenomenon has been afforded by the analysis of an MFGE8 (formerly known as SED1) knockout mouse model (Table 1). The epididymal epithelial cells of these mice are characterized by increased accumulation of intracellular vesicles and an apical distribution of VATPase. Such changes are, in turn, reflected in epididymal luminal environment, which displays abnormal osmolarity (i.e., hypo-osmotic) and alkalinity; suggestive of the existence of a positive feedback loop responsible for regulating the behavior of the epithelial cells in response to changes in the luminal environment (99).

\section{Membrane Trafficking Machinery Involved in the Regulation of the Epididymal Environment}

Despite recognition of the importance of bidirectional epithelial transport in regulating the epididymal luminal environment, little is currently known about the molecular machinery that controls these complementary pathways. Key elements are likely to include Soluble NSF Attachment Protein Receptor (SNARE) proteins, which have well-described roles in the regulation of membrane fusion activity in alternative tissue models. This activity requires the complementary action of different SNARE proteins contributed by vesicles (v-SNARE proteins) and target (t-SNARE proteins) membranes. Initiated by nucleation of the SNARE complex in response to calcium fluxes, the two opposing membranes are brought into close apposition and are thereafter able to engage in membrane fusion (100). The first evidence implicating SNARE proteins in the regulation of membrane fusion events in the epididymis arose from studies of the clear cell population (101). Functional analysis of these cells revealed that cellubrevin, a v-SNARE, is essential for acidification of the luminal environment. Accordingly, tetanus toxin-mediated cleavage of cellubrevin is able to inhibit proton secretion into the lumen (101). In addition to the lining epithelial cells, it is known that spermatozoa also harbor several t-SNARE and their cognate v-SNARE counterparts, which are localized to the plasma membrane and underlying outer acrosomal membranes, respectively. Such a location accords with the proposed role of SNARE proteins in regulating the membrane fusion events that underpin sperm acrosomal exocytosis (102-104). Notably however, this also ideally positions SNAREs to participate in the tethering of epididymosomes to the sperm surface and thereby facilitate the transfer of their cargo to the maturing cells. In agreement with this model, the requisite SNARE proteins necessary for constructing a functional membrane fusion complex have also been documented in epididymosomes $(53,101,102)$. Nevertheless, there is currently limited experimental evidence to support the role of SNARE complexes in the regulation of sperm maturation.

Aside from SNARE proteins, recent proteomic analyses of luminal fluids obtained from the bovine epididymis have revealed the presence of at least 13 proteins implicated in clathrin-mediated endocytosis. Since this form of endocytosis is unlikely to occur in spermatozoa, these proteins may instead contribute the recycling of epididymal components via uptake into the surrounding epithelial cells (105). In this context, alternative regulators of membrane trafficking belonging to the Rab superfamily of GTPases have also been documented within epididymal luminal fluid, and more specifically, as part of the proteome of both human and bull epididymosomes $(53,106)$. Such findings are of interest as the Rab superfamily, which consists of some 30 members, have been implicated in regulating various membrane trafficking events including vesicle formation, sorting, release, and cargo transfer to recipient cells $(100,107)$. It is therefore tempting to speculate that $\mathrm{Rab}$ proteins may participate in epididymosome-sperm interaction/cargo transfer.

An additional family of membrane-trafficking proteins that warrant further investigation in the context of regulating 
epididymal function is that of the dynamin family of large GTPases. Indeed, our recent studies have shown that canonical dynamin isoforms display both cell, and segment-specific, differences in their profile of expression in the mouse epididymis. Specifically, dynamin 1 and 3 are mainly expressed in the corpus and cauda segments where they localize within the clear cell and principal cell populations, respectively. Of note, the differential localization of these dynamin isoforms contrasts the overlapping and redundant roles they display in neuronal tissues (108), suggesting that they may fulfill discrete functions in the epididymal tubule. Moreover, dynamin 1 was shown to be delivered to human spermatozoa during epididymal transit, in a mechanism that may involve epididymosomes (109). This compares favorably with the mouse in which caput and cauda spermatozoa display different patterns of dynamin 1 labeling (79). At present however, it remains to be determined whether dynamin 1 forms part of the cargo transferred between epididymosomes and maturing spermatozoa, or alternatively if it is instead involved in the regulation of epididymosome docking/fusion with spermatozoa. In contrast to dynamin isoforms 1 and 3, dynamin 2 localizes strongly to the Golgi apparatus in principal cells of the proximal epididymal segments, consistent with a role in mediating post-Golgi vesicle trafficking in the most active secretory cells of the tract. In more distal segments, dynamin 2 is detected in the microvilli and apical blebs lining the luminal border, suggesting it may be participate in the regulation of apocrine secretion (79).

\section{Epididymosome-Mediated Sperm-Soma Intracellular Communication}

Among the varied molecular mechanisms that exert influence over the unique intraluminal environment of the epididymis, vesicle-dependent pathways of intercellular communication have emerged as being of fundamental importance. An obvious advantage afforded by the production of epididymosomes is the prospect of delivering macromolecular cargo to spermatozoa en masse. Additionally, the encapsulation of such cargo within a relatively stable membrane-bound structure could afford stability and protection against the potentially deleterious extracellular environment of the epididymal lumen. It is therefore perhaps not surprising that, in addition to their protein cargo, epididymosomes also comprise a heterogeneous population of small non-coding RNAs (sncRNA) including miRNA and tRNA fragments $(70,72)$. Like that of their protein cargo, these sncRNAs are available for direct transfer to the maturing spermatozoa. Accordingly, emerging work has shown that exposure of male mice to dietary perturbations (e.g., low protein diets) can markedly influence the sncRNA profiles of detected in the epididymis of these animals. Moreover, these changes are subsequently manifest in altered sperm sncRNA profiles, with epididymosomes having been implicated as the vector for delivery of this cargo to the maturing epididymal spermatozoa. Of some concern is the recognition that spermatozoa are subsequently able to relay these sncRNA to the oocyte during fertilization, whereupon they exert epigenetic control over early embryo development through targeting of a specific subset of genes (72). Such findings encourage a deeper understanding of the mechanisms underpinning the selective packaging of epididymosome cargo, the way in which this cargo is delivered to recipient cells (i.e., maturing spermatozoa and/ or downstream epithelial cells) and the degree to which these vectors regulate the acquisition of functional competence in maturing spermatozoa.

This field of research is somewhat confounded by the fact that epididymosomes represent a heterogeneous population of vesicles. In this context, it has been shown that bovine epididymosomes collected from different epididymal segments are capable of transferring differing protein repertories to spermatozoa. Further, an excess of one population of epididymosomes (collected from caput segment) does not overtly influence the transfer efficacy of the alternative population (collected from cauda segment) during simultaneous co-incubation with spermatozoa (49). As an extension of this work, it has also recently been shown that epididymosomes can be subdivided into two discrete subpopulations owing to their size and molecular composition. The smaller of these populations measure $\sim 10-100 \mathrm{~nm}$ in diameter and are distinguished based on the presence of tetraspanin-enriched microdomains containing both CD9 and its cooperative partner CD26. These epididymosomes also contain a relatively high concentration of proteins such as MIF and P25b, and display a preference to interact with live spermatozoa. These collective properties implicate this sub-class of epididymosomes in sperm maturation (110). The alternative subpopulation is characterized by the presence of epididymal sperm binding protein 1, and also by their propensity to interact with dead spermatozoa $(52,111)$. The overall heterogeneity of epididymosomes and their capacity to selectively interact with different sub-populations of spermatozoa suggests these interactions may be tightly regulated.

At present, however, the molecular mechanisms underpinning the biogenesis of different populations of epididymosomes, as well as those responsible for their interaction with spermatozoa remain to be established. Recent work has suggested the latter process may be initiated via the docking of GPI anchor(s) to the outer leaflet of the sperm surface lipid bilayer (87). Such docking is putatively followed by membrane fusion between the epididymosome and sperm membrane. In this regard, the adhesive/fusion properties of CD9 have identified this tetraspanin as a likely candidate in regulation of this fusion event $(112,113)$. Such a model is commensurate with the demonstration that anti-CD9 masking antibodies are able to reduce the efficacy of protein transfer from epididymosomes to spermatozoa (110). Notably, however, CD9 is unlikely to be the sole candidate since epididymosome-sperm interaction is characterized by a degree of selectivity in terms of the relayed content and their ability to discriminate between different populations of spermatozoa. As mentioned above, this is particularly the case in the bovine model where a subset of epididymosomes has been identified that do not possess CD9 and yet are still able to interact with spermatozoa (52). Owing to their role in receptor sequestration, lipid rafts have also been recently proposed as a "platform" to facilitate docking of the epididymosome and sperm membranes. Highly enriched in cholesterol and sphingolipid (114), these microdomains also compartmentalize GPI-anchored 
proteins such as P25b and SPAM1 (87) that themselves have been implicated in epididymosome-sperm adhesion. Thus, the release of P25b and SPAM1 proteins from sperm lipid rafts, via trypsin/pronase proteolysis, leads to a significant reduction in the efficacy of epididymosome cargo transfer to the sperm cells (115). However, it remains to be determined if the disruption of lipid raft integrity (e.g., through cholesterol sequestration using methyl- $\beta$-cyclodextrin) also compromises the docking of epididymosomes to the sperm surface.

Adding to this controversy is the suggestion that the interaction between epididymosomes and spermatozoa may not involve a complete fusion of their respective membranes (116). Rather, epididymosome adherence may be followed by creation of a transient fusion pore and subsequent release of the epididymosome once delivery of their cargo is complete. Accordingly, proteomic analyses of epididymosomes, and spermatozoa themselves, have identified a myriad of complementary trafficking proteins (e.g., SNARE proteins, Ras-like proteins, and dynamins) (53) that could regulate this form of intercellular communication. An intriguing aspect of this "kiss and run" model is that it could potentially facilitate bi-directional exchange of proteins and other macromolecules both into, and out of, the maturing sperm cell. It may also account for why a portion of epididymosomes persist in seminal fluids rather than being completely absorbed by spermatozoa within the duct. To the best of our knowledge, however, there is presently limited functional evidence linking any of the abovementioned trafficking proteins to a role in sperm-epididymosome interaction, and no evidence that epididymosomes can sequester proteins from spermatozoa. Irrespective, it has been shown that lipid labeled (Dilc12) epididymosomes originating from the median caput segment are able to be incorporated into distal caput epithelial cells in vitro (33). Such incorporation is time-dependent, with fluorescence imaging revealing a punctate distribution of Dilc12 within the epithelial cells after epididymosome interaction. This pattern of labeling is reminiscent of that observed after exosome interaction

\section{REFERENCES}

1. Benoit J. Recherches anatomiques, cytologiques et histophysiologiques, sur les voies excrétices du testicules chez les mammiferes. Arch Anat Histol Embryol (1926) 5:173-412.

2. Nixon B, Ecroyd H, Dacheux JL, Dacheux F, Labas V, Johnston SD, et al. Formation and dissociation of sperm bundles in monotremes. Biol Reprod (2016) 95:91. doi:10.1095/biolreprod.116.140491

3. Abe K, Takano H, Ito T. Microvasculature of the mouse epididymis, with special reference to fenestrated capillaries localized in the initial segment. Anat Rec (1984) 209:209-18. doi:10.1002/ar.1092090208

4. Aitken RJ, Nixon B, Lin M, Koppers AJ, Lee YH, Baker MA. Proteomic changes in mammalian spermatozoa during epididymal maturation. Asian J Androl (2007) 9:554-64. doi:10.1111/j.1745-7262.2007.00280.x

5. Bork K, Chevrier C, Paquignon M, Jouannet P, Dacheux JL. [Flagellar motility amd movement of boar spermatozoa during epididymal transit]. Reprod Nutr Dev (1988) 28:1307-15. doi:10.1051/rnd:19880811

6. Chevrier C, Dacheux JL. Evolution of the flagellar waveform of ram spermatozoa in relation to the degree of epididymal maturation. Cell Motil Cytoskeleton (1992) 23:8-18. doi:10.1002/cm.970230103

7. Hermo L, Dworkin J, Oko R. Role of epithelial clear cells of the rat epididymis in the disposal of the contents of cytoplasmic droplets detached from spermatozoa. Am J Anat (1988) 183:107-24. doi:10.1002/aja.1001830202 with somatic cells in other tissue models (117), thus indicating that sperm are not the sole recipients of epididymosome cargo.

\section{CONCLUSION}

The epididymal milieu is undoubtedly crucial for promoting sperm maturation as well as supporting their storage. Indeed, since sperm are transcriptionally and translationally silent cells, their functional transformation relies entirely on the creation and maintenance of a highly specialized epididymal luminal milieu. The establishment of this unique epididymal microenvironment features the varied endocytotic and exocytotic contributions of the epithelial cells that line the duct. Unfortunately, our understanding of the molecular machinery the epididymal epithelial cells employ to facilitate these processes remains incomplete, as does our knowledge of how these cells are precisely regulated in different segments. Resolving these questions promises to inform our understanding of male fertility regulation with implications for contraceptive intervention and infertility diagnostics.

\section{AUTHOR CONTRIBUTIONS}

All authors made substantial contributions to the conception of this review and the critical appraisal of the literature summarized herein. WZ generated the initial draft of the manuscript, and this was critically revised by $\mathrm{BN}, \mathrm{GD}$, and MD. All authors approved the final version and submission of this article.

\section{FUNDING}

This work was supported by National Health and Medical Research Council of Australia Project Grants (APP1103176 and APP1147932) to $\mathrm{BN}$ and $\mathrm{MD}$. WZ is supported by a $\mathrm{PhD}$ scholarship awarded by the University of Newcastle. MD is supported by a Cancer Institute New South Wales Early Career Fellowship. BN is supported by an Australian Research Council Future Fellowship (FT140101368).

8. Robaire B, Hinton B, Orgebin-Crist M. The Epididymis, Knobil and Neill's Physiology of Reproduction. New York: Elsevier (2006).

9. Turner TT. Resorption versus secretion in the rat epididymis. J Reprod Fertil (1984) 72:509-14. doi:10.1530/jrf.0.0720509

10. Cornwall GA. New insights into epididymal biology and function. Hum Reprod Update (2009) 15:213-27. doi:10.1093/humupd/dmn055

11. Abe K, Takano H, Ito T. Ultrastructure of the mouse epididymal duct with special reference to the regional differences of the principal cells. Arch Histol Jpn (1983) 46:51-68. doi:10.1679/aohc.46.51

12. Hermo L, Robaire B. Epididymal cell types and their functions. In: Robaire B, Hinton BT, editors. The Epididymis: From Molecules to Clinical Practice. Boston, MA: Springer (2002). p. 81-102.

13. Dacheux JL, Belleannee C, Jones R, Labas V, Belghazi M, Guyonnet B, et al. Mammalian epididymal proteome. Mol Cell Endocrinol (2009) 306:45-50. doi:10.1016/j.mce.2009.03.007

14. Brown D, Smith PJ, Breton S. Role of V-ATPase-rich cells in acidification of the male reproductive tract. J Exp Biol (1997) 200:257-62.

15. Adamali HF, Hermo L. Apical and narrow cells are distinct cell types differing in their structure, distribution, and functions in the adult rat epididymis. J Androl (1996) 17:208-22.

16. Sun EL, Flickinger CJ. Morphological characteristics of cells with apical nuclei in the initial segment of the adult rat epididymis. Anat Rec (1980) 196:285-93. doi:10.1002/ar.1091960304 
17. Hermo L, Papp S. Effects of ligation, orchidectomy, and hypophysectomy on expression of the Yf subunit of GST-P in principal and basal cells of the adult rat epididymis and on basal cell shape and overall arrangement. Anat Rec (1996) 244:59-69. doi:10.1002/(SICI) 1097-0185(199601)244:1<59::AIDAR6>3.0.CO;2-A

18. Jelinsky SA, Turner TT, Bang HJ, Finger JN, Solarz MK, Wilson E, et al. The rat epididymal transcriptome: comparison of segmental gene expression in the rat and mouse epididymides. Biol Reprod (2007) 76:561-70. doi:10.1095/biolreprod.106.057323

19. Wong PYD, Gong XD, Leung GPH, Cheuk BLY. Formation of the epididymal fluid microenvironment. In: Robaire B, Hinton BT, editors. The Epididymis: From Molecules to Clinical Practice. Boston, MA: Springer (2002). p. 119-30.

20. Turner TT, Hinton BT. The Third International Conference on the Epididymis. Charlottesville, VA: The Van Doren Company (2003).

21. Johnston DS, Jelinsky SA, Bang HJ, DiCandeloro P, Wilson E, Kopf GS, et al. The mouse epididymal transcriptome: transcriptional profiling of segmental gene expression in the epididymis. Biol Reprod (2005) 73:404-13. doi:10.1095/biolreprod.105.039719

22. Nixon B, Stanger SJ, Mihalas BP, Reilly JN, Anderson AL, Dun MD, et al. Next generation sequencing analysis reveals segmental patterns of microRNA expression in mouse epididymal epithelial cells. PLoS One (2015) 10:e0135605. doi:10.1371/journal.pone.0135605

23. Skerget S, Rosenow MA, Petritis K, Karr TL. Sperm proteome maturation in the mouse epididymis. PLoS One (2015) 10:e0140650. doi:10.1371/journal. pone. 0140650

24. Garrett SH, Garrett JE, Douglass J. In situ histochemical analysis of region-specific gene expression in the adult rat epididymis. Mol Reprod Dev (1991) 30:1-17. doi:10.1002/mrd.1080300102

25. Cornwall GA, Orgebincrist MC, Hann SR. The CRES gene - a unique testis-regulated gene related to the cystatin family is highly restricted in its expression to the proximal region of the mouse epididymis. Mol Endocrinol (1992) 6:1653-64. doi:10.1210/me.6.10.1653

26. Lareyre JJ, Thomas TZ, Zheng WL, Kasper S, Ong DE, Orgebin-Crist MC, et al. A 5-kilobase pair promoter fragment of the murine epididymal retinoic acid-binding protein gene drives the tissue-specific, cell-specific, and androgenregulated expression of a foreign gene in the epididymis of transgenic mice. J Biol Chem (1999) 274:8282-90. doi:10.1074/jbc.274.12.8282

27. Guyonnet B, Marot G, Dacheux JL, Mercat MJ, Schwob S, Jaffrezic F, et al. The adult boar testicular and epididymal transcriptomes. BMC Genomics (2009) 10:369. doi:10.1186/1471-2164-10-369

28. Browne JA, Yang R, Leir SH, Eggener SE, Harris A. Expression profiles of human epididymis epithelial cells reveal the functional diversity of caput, corpus and cauda regions. Mol Hum Reprod (2016) 22:69-82. doi:10.1093/ molehr/gav066

29. Li Y, Wang HY, Wan FC, Liu FJ, Liu J, Zhang N, et al. Deep sequencing analysis of small non-coding RNAs reveals the diversity of microRNAs and piRNAs in the human epididymis. Gene (2012) 497:330-5. doi:10.1016/j. gene.2012.01.038

30. Zhang J, Liu Q, Zhang W, Li J, Li Z, Tang Z, et al. Comparative profiling of genes and miRNAs expressed in the newborn, young adult, and aged human epididymides. Acta Biochim Biophys Sin (2010) 42:145-53. doi:10.1093/abbs/ gmp116

31. Zhang YL, Zhang JS, Zhou YC, Zhao Y, Ni MJ. Identification of microRNAs and application of RNA interference for gene targeting in vivo in the rat epididymis. J Androl (2011) 32:587-91. doi:10.2164/jandrol.111.013060

32. Belleannee C, Calvo E, Thimon V, Cyr DG, Legare C, Garneau L, et al. Role of microRNAs in controlling gene expression in different segments of the human epididymis. PLoS One (2012) 7:e34996. doi:10.1371/journal. pone.0034996

33. Belleannee C, Calvo E, Caballero J, Sullivan R. Epididymosomes convey different repertoires of microRNAs throughout the bovine epididymis. Biol Reprod (2013) 89:30. doi:10.1095/biolreprod.113.110486

34. Wong N, Wang X. miRDB: an online resource for microRNA target prediction and functional annotations. Nucleic Acids Res (2015) 43:D146-52. doi:10.1093/nar/gku1104

35. Ma W, Hu S, Yao G, Xie S, Ni M, Liu Q, et al. An androgen receptormicrorna-29a regulatory circuitry in mouse epididymis. J Biol Chem (2013) 288:29369-81. doi:10.1074/jbc.M113.454066
36. Villarroya-Beltri C, Gutiérrez-Vázquez C, Sánchez-Cabo F, PérezHernández D, Vázquez J, Martin-Cofreces N, et al. Sumoylated hnRNPA2B1 controls the sorting of miRNAs into exosomes through binding to specific motifs. Nat Commun (2013) 4:2980. doi:10.1038/ncomms3980

37. Ecroyd H, Belghazi M, Dacheux JL, Gatti JL. The epididymal soluble prion protein forms a high-molecular-mass complex in association with hydrophobic proteins. Biochem J (2005) 392:211-9. doi:10.1042/BJ20050459

38. Díaz-Flores L, Gutiérrez R, del Pino Garcia M, Gayoso MJ, Carrasco JL, Díaz-Flores L Jr, et al. Localized amyloidosis of the epididymis: a previously unreported phenomenon. Diagn Pathol (2017) 12:58. doi:10.1186/ s13000-017-0646-z

39. Asquith KL, Harman AJ, McLaughlin EA, Nixon B, Aitken RJ. Localization and significance of molecular chaperones, heat shock protein 1, and tumor rejection antigen gp96 in the male reproductive tract and during capacitation and acrosome reaction. Biol Reprod (2005) 72:328-37. doi:10.1095/ biolreprod.104.034470

40. Whelly S, Johnson S, Powell J, Borchardt C, Hastert MC, Cornwall GA. Nonpathological extracellular amyloid is present during normal epididymal sperm maturation. PLoS One (2012) 7:e36394. doi:10.1371/journal. pone. 0036394

41. Whelly S, Muthusubramanian A, Powell J, Johnson S, Hastert MC, Cornwall GA. Cystatin-related epididymal spermatogenic subgroup members are part of an amyloid matrix and associated with extracellular vesicles in the mouse epididymal lumen. Mol Hum Reprod (2016) 22:729-44. doi:10.1093/ molehr/gaw049

42. Hewetson A, Do HQ, Myers C, Muthusubramanian A, Sutton RB, Wylie BJ, et al. Functional amyloids in reproduction. Biomolecules (2017) 7:46. doi:10.3390/biom7030046

43. Yano R, Matsuyama T, Kaneko T, Kurio H, Murayama E, Toshimori K, et al. Bactericidal/permeability-increasing protein is associated with the acrosome region of rodent epididymal spermatozoa. JAndrol (2010) 31:201-14. doi:10.2164/jandrol.109.007880

44. Reid AT, Anderson AL, Roman SD, McLaughlin EA, McCluskey A, Robinson $\mathrm{PJ}$, et al. Glycogen synthase kinase 3 regulates acrosomal exocytosis in mouse spermatozoa via dynamin phosphorylation. FASEB J (2015) 29:2872-82. doi:10.1096/fj.14-265553

45. Yanagimachi R, Kamiguchi Y, Mikamo K, Suzuki F, Yanagimachi H. Maturation of spermatozoa in the epididymis of the Chinese hamster. Am J Anat (1985) 172:317-30. doi:10.1002/aja.1001720406

46. Rejraji H, Sion B, Prensier G, Carreras M, Motta C, Frenoux JM, et al. Lipid remodeling of murine epididymosomes and spermatozoa during epididymal maturation. Biol Reprod (2006) 74:1104-13. doi:10.1095/biolreprod. 105.049304

47. Fornes MW, Barbieri A, Cavicchia JC. Morphological and enzymatic study of membrane-bound vesicles from the lumen of the rat epididymis. Andrologia (1995) 27:1-5. doi:10.1111/j.1439-0272.1995.tb02087.x

48. Frenette G, Sullivan R. Prostasome-like particles are involved in the transfer of P25b from the bovine epididymal fluid to the sperm surface. Mol Reprod $\operatorname{Dev}$ (2001) 59:115-21. doi:10.1002/mrd.1013

49. Frenette G, Girouard J, Sullivan R. Comparison between epididymosomes collected in the intraluminal compartment of the bovine caput and cauda epididymidis. Biol Reprod (2006) 75:885-90. doi:10.1095/biolreprod.106.054692

50. Thimon V, Frenette G, Saez F, Thabet M, Sullivan R. Protein composition of human epididymosomes collected during surgical vasectomy reversal: a proteomic and genomic approach. Hum Reprod (2008) 23:1698-707. doi:10.1093/humrep/den181

51. Sullivan R, Saez F, Girouard J, Frenette G. Role of exosomes in sperm maturation during the transit along the male reproductive tract. Blood Cells $\mathrm{Mol}$ Dis (2005) 35:1-10. doi:10.1016/j.bcmd.2005.03.005

52. Sullivan R. Epididymosomes: a heterogeneous population of microvesicles with multiple functions in sperm maturation and storage. Asian J Androl (2015) 17:726-9. doi:10.4103/1008-682X.155255

53. Girouard J, Frenette G, Sullivan R. Comparative proteome and lipid profiles of bovine epididymosomes collected in the intraluminal compartment of the caput and cauda epididymidis. Int J Androl (2011) 34:e475-86. doi:10.1111/j.1365-2605.2011.01203.x

54. Frenette G, Lessard C, Madore E, Fortier MA, Sullivan R. Aldose reductase and macrophage migration inhibitory factor are associated with epididymosomes 
and spermatozoa in the bovine epididymis. Biol Reprod (2003) 69:1586-92. doi:10.1095/biolreprod.103.019216

55. Eickhoff R, Baldauf C, Koyro HW, Wennemuth G, Suga Y, Seitz J, et al. Influence of macrophage migration inhibitory factor (MIF) on the zinc content and redox state of protein-bound sulphydryl groups in rat sperm: indications for a new role of MIF in sperm maturation. Mol Hum Reprod (2004) 10:605-11. doi:10.1093/molehr/gah075

56. Légaré $\mathrm{C}$, Bérubé B, Boué F, Lefièvre L, Morales CR, El-Alfy M, et al. Hamster sperm antigen P26h is a phosphatidylinositol-anchored protein. Mol Reprod Dev (1999) 52:225-33. doi:10.1002/(SICI)1098-2795(199902)52:2<225:: AID-MRD14>3.0.CO;2-M

57. Boue F, Blais J, Sullivan R. Surface localization of P34H an epididymal protein, during maturation, capacitation, and acrosome reaction of human spermatozoa. Biol Reprod (1996) 54:1009-17. doi:10.1095/biolreprod54. 5.1009

58. Berube B, Sullivan R. Inhibition of in vivo fertilization by active immunization of male hamsters against a $26-\mathrm{kDa}$ sperm glycoprotein. Biol Reprod (1994) 51:1255-63. doi:10.1095/biolreprod51.6.1255

59. Patel R, Al-Dossary AA, Stabley DL, Barone C, Galileo DS, Strehler EE, et al. Plasma membrane Ca2+-ATPase 4 in murine epididymis: secretion of splice variants in the luminal fluid and a role in sperm maturation. Biol Reprod (2013) 89:6. doi:10.1095/biolreprod.113.108712

60. Mawson CA, Fischer MI. Zinc content of the genital organs of the rat. Nature (1951) 167:859. doi:10.1038/167859a0

61. Wales RG, Wallace JC, White IG. Composition of bull epididymal and testicular fluid. J Reprod Fertil (1966) 12:139-44. doi:10.1530/jrf.0.0120139

62. Levine N, Marsh DJ. Micropuncture studies of the electrochemical aspects of fluid and electrolyte transport in individual seminiferous tubules, the epididymis and the vas deferens in rats. J Physiol (1971) 213:557-70. doi:10.1113/ jphysiol.1971.sp009400

63. Jenkins $\mathrm{AD}$, Lechene $\mathrm{CP}$, Howards SS. Concentrations of seven elements in the intraluminal fluids of the rat seminiferous tubules, rete testis, and epididymis. Biol Reprod (1980) 23:981-7. doi:10.1095/biolreprod23.5.981

64. Jones RC, Clulow J. Regulation of the elemental composition of the epididymal fluids in the tammar, Macropus engenii. J Reprod Fertil (1987) 81:583-90. doi:10.1530/jrf.0.0810583

65. Morton BE, Sagadraca R, Fraser C. Sperm motility within the mammalian epididymis: species variation and correlation with free calcium levels in epididymal plasma. Fertil Steril (1978) 29:695-8. doi:10.1016/S0015-0282 (16)43348-0

66. Shum WW, Ruan YC, Da Silva N, Breton S. Establishment of cell-cell cross talk in the epididymis: control of luminal acidification. J Androl (2011) 32:576-86. doi:10.2164/jandrol.111.012971

67. Breton S, Ruan YC, Park YJ, Kim B. Regulation of epithelial function, differentiation, and remodeling in the epididymis. Asian J Androl (2016) 18:3-9. doi:10.4103/1008-682X.165946

68. Beaulieu V, Da Silva N, Pastor-Soler N, Brown CR, Smith PJ, Brown D, et al. Modulation of the actin cytoskeleton via gelsolin regulates vacuolar H+-ATPase recycling. J Biol Chem (2005) 280:8452-63. doi:10.1074/jbc. M412750200

69. Ren D, Navarro B, Perez G, Jackson AC, Hsu S, Shi Q, et al. A sperm ion channel required for sperm motility and male fertility. Nature (2001) 413: 603-9. doi:10.1038/35098027

70. Reilly JN, McLaughlin EA, Stanger SJ, Anderson AL, Hutcheon K, Church K, et al. Characterisation of mouse epididymosomes reveals a complex profile of microRNAs and a potential mechanism for modification of the sperm epigenome. Sci Rep (2016) 6:31794. doi:10.1038/srep31794

71. Hutcheon K, McLaughlin EA, Stanger SJ, Bernstein IR, Dun MD, Eamens AL. Analysis of the small non-protein-coding RNA profile of mouse spermatozoa reveals specific enrichment of piRNAs within mature spermatozoa. RNA Biol (2017) 14:1-15. doi:10.1080/15476286.2017.1356569

72. Sharma U, Conine CC, Shea JM, Boskovic A, Derr AG, Bing XY, et al. Biogenesis and function of tRNA fragments during sperm maturation and fertilization in mammals. Science (2016) 351:391-6. doi:10.1126/science. aad6780

73. Nixon B, Stanger SJ, Mihalas BP, Reilly JN, Anderson AL, Tyagi S, et al. The microRNA signature of mouse spermatozoa is substantially modified during epididymal maturation. Biol Reprod (2015) 93(91):1-20. doi:10.1095/ biolreprod.115.132209
74. Eaton SA, Jayasooriah N, Buckland ME, Martin DI, Cropley JE, Suter CM. Roll over Weismann: extracellular vesicles in the transgenerational transmission of environmental effects. Epigenomics (2015) 7:1165-71. doi:10.2217/epi.15.58

75. Hermo L, Oko R, Morales CR. Secretion and endocytosis in the male reproductive tract: a role in sperm maturation. Int Rev Cytol (1994) 154:106-89.

76. Dacheux JL, Castella S, Gatti JL, Dacheux F. Epididymal cell secretory activities and the role of proteins in boar sperm maturation. Theriogenology (2005) 63:319-41. doi:10.1016/j.theriogenology.2004.09.015

77. Cooper TG. Epididymal research: more warp than weft? Asian J Androl (2015) 17:699-703. doi:10.4103/1008-682X.146102

78. Gomi H, Mori K, Itohara S, Izumi T. Rab27b is expressed in a wide range of exocytic cells and involved in the delivery of secretory granules near the plasma membrane. Mol Biol Cell (2007) 18:4377-86. doi:10.1091/mbc. E07-05-0409

79. Zhou W, De Iuliis GN, Turner AP, Reid AT, Anderson AL, McCluskey A, et al. Developmental expression of the dynamin family of mechanoenzymes in the mouse epididymis. Biol Reprod (2017) 96:159-73. doi:10.1095/ biolreprod.116.145433

80. Kreitzer G, Marmorstein A, Okamoto P, Vallee R, Rodriguez-Boulan E. Kinesin and dynamin are required for post-Golgi transport of a plasmamembrane protein. Nat Cell Biol (2000) 2:125-7. doi:10.1038/35000081

81. Weller SG, Capitani M, Cao H, Micaroni M, Luini A, Sallese M, et al. Src kinase regulates the integrity and function of the Golgi apparatus via activation of dynamin 2. Proc Natl Acad Sci U S A (2010) 107:5863-8. doi:10.1073/pnas.0915123107

82. González-Jamett AM, Momboisse F, Haro-Acuña V, Bevilacqua JA, Caviedes P, Cárdenas AM. Dynamin-2 function and dysfunction along the secretory pathway. Front Endocrinol (2013) 4:126. doi:10.3389/fendo.2013.00126

83. Jackson J, Papadopulos A, Meunier FA, McCluskey A, Robinson PJ, Keating DJ. Small molecules demonstrate the role of dynamin as a bi-directional regulator of the exocytosis fusion pore and vesicle release. Mol Psychiatry (2015) 20:810-9. doi:10.1038/mp.2015.56

84. Williams M, Kim K. From membranes to organelles: emerging roles for dynamin-like proteins in diverse cellular processes. Eur J Cell Biol (2014) 93:267-77. doi:10.1016/j.ejcb.2014.05.002

85. Menon M, Schafer DA. Dynamin: expanding its scope to the cytoskeleton. Int Rev Cell Mol Biol (2013) 302:187-219. doi:10.1016/B978-0-12-4076990.00003-0

86. Sullivan R, Frenette G, Girouard J. Epididymosomes are involved in the acquisition of new sperm proteins during epididymal transit. Asian J Androl (2007) 9:483-91. doi:10.1111/j.1745-7262.2007.00281.x

87. Griffiths GS, Galileo DS, Reese K, Martin-Deleon PA. Investigating the role of murine epididymosomes and uterosomes in GPI-linked protein transfer to sperm using SPAM1 as a model. Mol Reprod Dev (2008) 75:1627-36. doi:10.1002/mrd.20907

88. Hermo L, Jacks D. Nature's ingenuity: bypassing the classical secretory route via apocrine secretion. Mol Reprod Dev (2002) 63:394-410. doi:10.1002/ mrd.90023

89. Aumuller G, Wilhelm B, Seitz J. Apocrine secretion - fact or artifact? Ann Anat (1999) 181:437-46. doi:10.1016/S0940-9602(99)80020-X

90. Andersen OM, Yeung CH, Vorum H, Wellner M, Andreassen TK, Erdmann B, et al. Essential role of the apolipoprotein E receptor-2 in sperm development. J Biol Chem (2003) 278:23989-95. doi:10.1074/jbc.M302157200

91. Hermo L, Barin K, Oko R. Androgen binding protein secretion and endocytosis by principal cells in the adult rat epididymis and during postnatal development. J Androl (1998) 19:527-41.

92. Djakiew D, Griswold MD, Lewis DM, Dym M. Micropuncture studies of receptor-mediated endocytosis of transferrin in the rat epididymis. Biol Reprod (1986) 34:691-9. doi:10.1095/biolreprod34.4.691

93. Djakiew D, Byers SW, Lewis DM, Dym M. Receptor-mediated endocytosis of Alpha2-macroglobulin by principal cells in the proximal caput epididymidis in vivo. J Androl (1985) 6:190-6. doi:10.1002/j.1939-4640.1985. tb00835.x

94. Axnér E. Sperm maturation in the domestic cat. Theriogenology (2006) 66:14-24. doi:10.1016/j.theriogenology.2006.03.022

95. Hermo L, Oko R, Robaire B. Epithelial-cells of the epididymis show regional variations with respect to the secretion or endocytosis of immobilin as revealed by light and electron-microscope immunocytochemistry. Anat Rec (1992) 232:202-20. doi:10.1002/ar.1092320206 
96. Castella S, Benedetti H, de Llorens R, Dacheux JL, Dacheux F. Train A, an RNase A-like protein without RNase activity, is secreted and reabsorbed by the same epididymal cells under testicular control. Biol Reprod (2004) 71:1677-87. doi:10.1095/biolreprod.104.031666

97. Morales CR, Igdoura SA, Wosu UA, Boman J, Argraves WS. Low density lipoprotein receptor-related protein-2 expression in efferent duct and epididymal epithelia: evidence in rats for its in vivo role in endocytosis of apolipoprotein J/clusterin. Biol Reprod (1996) 55:676-83. doi:10.1095/ biolreprod55.3.676

98. Oliveira CA, VictorCosta AB, Hess RA. Cellular and regional distributions of ubiquitin proteasome and endocytotic pathway components in the epithelium of rat efferent ductules and initial segment of the epididymis. J Androl (2009) 30:590-601. doi:10.2164/jandrol.108.007310

99. Raymond AS, Elder B, Ensslin M, Shur BD. Loss of SED1/MFG-E8 results in altered luminal physiology in the epididymis. Mol Reprod Dev (2010) 77:550-63. doi:10.1002/mrd.21189

100. Lin RC, Scheller RH. Mechanisms of synaptic vesicle exocytosis. Annu Rev Cell Dev Biol (2000) 16:19-49. doi:10.1146/annurev.cellbio.16.1.19

101. Breton S, Nsumu NN, Galli T, Sabolic I, Smith PJ, Brown D. Tetanus toxin-mediated cleavage of cellubrevin inhibits proton secretion in the male reproductive tract. Am J Physiol Renal Physiol (2000) 278:F717-25. doi:10.1152/ajprenal.2000.278.5.F717

102. Tomes CN, Michaut M, De Blas G, Visconti P, Matti U, Mayorga LS. SNARE complex assembly is required for human sperm acrosome reaction. Dev Biol (2002) 243:326-38. doi:10.1006/dbio.2002.0567

103. Zhao L, Shi X, Li L, Miller DJ. Dynamin 2 associates with complexins and is found in the acrosomal region of mammalian sperm. Mol Reprod Dev (2007) 74:750-7. doi:10.1002/mrd.20660

104. Garcia MA, Meizel S. Progesterone-mediated calcium influx and acrosome reaction of human spermatozoa: pharmacological investigation of T-type calcium channels. Biol Reprod (1999) 60:102-9. doi:10.1095/biolreprod60. 1.102

105. Westfalewicz B, Dietrich MA, Mostek A, Partyka A, Bielas W, Niżański W, et al. Identification and functional analysis of bull (Bos taurus) cauda epididymal fluid proteome. J Dairy Sci (2017) 100:6707-19. doi:10.3168/ jds.2016-12526

106. Belleannée C, Labas V, Teixeira-Gomes AP, Gatti JL, Dacheux JL, Dacheux F. Identification of luminal and secreted proteins in bull epididymis. J Proteomics (2011) 74:59-78. doi:10.1016/j.jprot.2010.07.013

107. Geppert M, Südhof TC. RAB3 and synaptotagmin: the yin and yang of synaptic membrane fusion. Annu Rev Neurosci (1998) 21:75-95. doi:10.1146/ annurev.neuro.21.1.75
108. Raimondi A, Ferguson SM, Lou X, Armbruster M, Paradise S, Giovedi S, et al. Overlapping role of dynamin isoforms in synaptic vesicle endocytosis. Neuron (2011) 70:1100-14. doi:10.1016/j.neuron.2011.04.031

109. Zhou W, Anderson AL, Turner AP, De Iuliis GN, McCluskey A, McLaughlin EA, et al. Characterization of a novel role for the dynamin mechanoenzymes in the regulation of human sperm acrosomal exocytosis. Mol Hum Reprod (2017) 23:657-73. doi:10.1093/molehr/gax044

110. Caballero JN, Frenette G, Belleannee C, Sullivan R. CD9-positive microvesicles mediate the transfer of molecules to bovine spermatozoa during epididymal maturation. PLoS One (2013) 8:e65364. doi:10.1371/journal. pone.0065364

111. D'Amours O, Frenette G, Caron P, Belleannee C, Guillemette C, Sullivan R. Evidences of biological functions of biliverdin reductase $\mathrm{A}$ in the bovine epididymis. J Cell Physiol (2016) 231:1077-89. doi:10.1002/jcp.25200

112. Thery C, Zitvogel L, Amigorena S. Exosomes: composition, biogenesis and function. Nat Rev Immunol (2002) 2:569-79. doi:10.1038/nri855

113. Thery C, Ostrowski M, Segura E. Membrane vesicles as conveyors of immune responses. Nat Rev Immunol (2009) 9:581-93. doi:10.1038/nri2567

114. Harroun TA, Katsaras J, Wassall SR. Cholesterol is found to reside in the center of a polyunsaturated lipid membrane. Biochemistry (2008) 47:7090-6. doi:10.1021/bi800123b

115. Girouard J, Frenette G, Sullivan R. Compartmentalization of proteins in epididymosomes coordinates the association of epididymal proteins with the different functional structures of bovine spermatozoa. Biol Reprod (2009) 80:965-72. doi:10.1095/biolreprod.108.073551

116. Gatti JL, Métayer S, Belghazi M, Dacheux F, Dacheux JL. Identification, proteomic profiling, and origin of ram epididymal fluid exosome-like vesicles. Biol Reprod (2005) 72:1452-65. doi:10.1095/biolreprod.104.036426

117. Tian T, Wang Y, Wang H, Zhu Z, Xiao Z. Visualizing of the cellular uptake and intracellular trafficking of exosomes by live-cell microscopy. J Cell Biochem (2010) 111:488-96. doi:10.1002/jcb.22733

Conflict of Interest Statement: The authors declare that this manuscript was prepared in the absence of any commercial or financial relationships or activities that could be construed as a potential conflict of interest.

Copyright (C) 2018 Zhou, De Iuliis, Dun and Nixon. This is an open-access article distributed under the terms of the Creative Commons Attribution License (CC BY). The use, distribution or reproduction in other forums is permitted, provided the original author(s) and the copyright owner are credited and that the original publication in this journal is cited, in accordance with accepted academic practice. No use, distribution or reproduction is permitted which does not comply with these terms. 